\title{
The Outcomes of Percutaneous Coronary Intervention in Chronic Total Coronary Occlusion: A Single Center Report
}

\author{
AKM Fazlur Rahman1, Mohammad Salman², Sajal K. Banerjee1, Khairul Anam¹, Mukhlesur Rahman, \\ Md. Khurshed Ahmed ${ }^{1}$, SM Mustafa Zaman ${ }^{1}$, Ahsan Habib ${ }^{1}$, Md. Abu Siddique ${ }^{1}$, KMHS Sirajul Haque ${ }^{1}$, \\ Choudhury Meshkat Ahmed ${ }^{1}$, Mohmmad Safiuddin ${ }^{1}$, Mir Jamiluddin ${ }^{3}$, Nilufar Fatema ${ }^{1}$, Md. Harisul Hoque ${ }^{1}$ \\ ${ }^{1}$ Department of Cardiology, Bangabandhu Sheikh Mujib Medical University, (BSMMU), Shahbag, Dhaka \\ ${ }^{2}$ Anwer Khan Modern Medical College, Dhanmondi, Dhaka \\ ${ }^{3}$ Department of Cardiology, National Institute of Cardiovascular Diseases (NICVD), Dhaka.
}

\author{
Address for Correspondence \\ Dr. AKM Fazlur Rahman, Associate Professor, Department of Cardiology, \\ Bangabandhu Sheikh Mujib Medical University, Shahbag, Dhaka \\ e-mail : frahman.card@yahoo.com
}

\begin{abstract}
Chronic total occlusions (CTOS) are commonly found on diagnostic angiography, and successful percutaneous coronary intervention leads to an improvement in long-term survival rates. This study was done in the University Cardiac Center, Department of Cardiology, Bangabandhu Sheikh Mujib Medical University, Dhaka, from January 2005 to December 2009. The aim of this study was to examine the trends in angiographic success, clinical success, procedural success and in-hospital outcomes after percutaneous coronary intervention (PCI) for chronic total occlusions (CTO). Total 60 patients (male: female, 11:1) with Mean age 48 \pm 10 years were studied. $36(60 \%)$ patients had prior myocardial infarction and all of them had angina (CCS-III, IV). Mean length and reference diameter of the CTO lesion was $19.7 \pm 10.4 \mathrm{~mm}$ and $2.8 \pm 0.5 \mathrm{~mm}$ respectably. Clinical success, angiographic success and procedural success rate was $(78.3 \%),(80.0 \%)$ and $(66.7 \%)$ respectably. In hospital adverse outcomes were acute myocardial infarction (5.0\%), acute left ventricular failure (6.7\%) and malignant arrhythmias (VT, VF) (10.0\%). PCI was failed in (11.7\%) cases and there was acute in-stent thrombosis in (1.7\%) cases. In conclusion it is possible to obtain a relatively high success rate of PCI and favorable clinical outcomes for patients with coronary СТO lesions.
\end{abstract}

Key words : Chronic total occlusions, In hospital adverse outcomes, Percutaneous coronary intervention,

\section{Introduction}

Chronic total occlusions (СТO) are still considered to be a challenge for the interventional cardiologist. It has been estimated that approximately $10 \%$ of all angioplasty procedures are currently undertaken for chronic total occlusions ${ }^{1}$. Percutaneous coronary intervention (PCI) of CTOs have been limited by a relatively low angiographic success rate between $42-73 \% .1,2$ However, a successful percutaneous coronary intervention of an occluded artery can improve clinical symptoms and left ventricular function and can even reduce coronary artery bypass graft surgery in this type of patient.

Chronic total occlusion (СТО) is defined as occlusion of a native coronary artery with no luminal continuity and with TIMI (Thrombolysis in Myocardial Infarction Trial) flow grade 0 or 1 . The duration of occlusion had to be 30 or more days. $^{3}$

Rationale for opening CTOs is to relieve angina pectoris or inducible myocardial ischemia occurring as a result of the occluded vessel, as an alternative to CABG. Others include improvement of left ventricular (LV) function and the improvement in long term survival.

Factors which predict a lower procedural success rate include length of occlusion $>15 \mathrm{~mm}$, duration of occlusion $>3$ months, presence of calcification in lesion and/or artery, and the presence of bridging collaterals. A "tapered-tip" occlusion is more favorable than a blunt "cut-off", as is the absence of side branches in close proximity to the occlusion. 4,5

There are limited published data on the short- and long-term outcomes after PCI for СТO in contemporary practice. Previous studies on СТо have suggested that there has been an improvement in procedural success over time. ${ }^{6}$ Comparison between long- and short-term outcomes to establish temporal trends is difficult because of the variable inclusion criteria, definitions of procedural success, clinical end points and long term follow up especially in our country. In this study we sought to explore the relationship 
between procedural success and incidence of in-hospital major adverse cardiac events (MACE) for interventional treatment of CTO.

\section{Materials and Methods}

This study was carried out in the Department of Cardiology, University Cardiac Center, Bangabandhu Sheikh Mujib Medical University, Dhaka, from January 2005 to December 2009. Total 60 consecutive patients (55 men, 5 women) with chronic total occlusion (СТO) were studied. All the patients had symptomatic angina and/or documented myocardial ischemia. All of these patients gave written informed consent, and the study was approved by the ethics committee of the Bangabandhu Sheikh Mujib Medical University, Dhaka. Patients with end-stage cancer with anticipated life span less than 6 months, severe renal failure with endogenous creatinine clearance rate $<30 \mathrm{ml} / \mathrm{min}$ or on dialysis, intracranial hemorrhage within 1 year or cerebral infarction within half a year were excluded from the study.

Definitions: А СТO was defined as a lesion exhibiting a Thrombolysis in Myocardial Infarction (TIMI) flow grade of $0-1$ in a native coronary artery, with a duration of occlusion of more than one month. ${ }^{4}$ The age of the СTO was determined, using clinical information, such as the past history of myocardial infarction, changes in the pattern of chest pain, or findings of total occlusion from previous coronary angiography. Early chronic occlusion was defined as total occlusion of a one to three month duration, and late chronic occlusion was defined as total occlusion with a duration longer than three months. ${ }^{4}$ The morphology at the point of occlusion was defined as either a tapered or abrupt end. ${ }^{7}$ The length of the occlusion was measured from the occlusion to the distal portion of the vessel filled by collateral flow or by the length of significant stenosis seen after passing the wire or predilated balloon catheter. The extent of collateral circulation was defined, according to the definition of Cohen and Rentrop. ${ }^{8}$

Interventional procedure: Routine dosage of aspirin and clopidogrel was prescribed to all patients before and after procedure. A bolus of 10000 Units heparin was injected at the beginning of procedure and followed by additional injections of 2500 units to keep the activated clotting time above 250 seconds during the procedure. Low-molecularweight heparin was administrated for 3 to 5 days after procedure. No glycoprotein IIb/IIIa inhibitors were used. All PCI procedures were performed using standard femoral approach as described by Gruentzig. A 7 Fr Judkins (Cordis, Johnson \& Johnson, USA), Amplatz (Cordis, Johnson \& Johnson, USA), Extra Back Up (Medtronic, USA), Voda (Boston Scientific, USA) and Multi Purpose (Cordis, Johnson \& Johnson, USA) guiding catheter with movable guide wire were used as needed. Initially flexible wire is used for crossing the lesion later on intermediate or hard wire is used as required. Buddy wire (track wire) technique is used if required. Successful PCI was defined as reduction of angiographic stenosis in СТО by approximately $50 \%$ or more. Coronary angiograms were obtained after the successful PCI to exclude any distal thrombi or pruning of small vessels. ECG were done before and 2, 12 and 16 hours of the procedure. Regular follow up and observation of MACE were done during the hospital stay of the patients.

\section{Statistical analysis}

Statistical analysis was done by SPSS (Statistical Package for Social Science) software for windows version 12.0. Data were expressed in number, percent or mean $\pm \mathrm{SD}$.

\section{Results}

\section{Base line clinical characteristics}

The baseline clinical characteristics of 60 cases underwent PCI for СТO are listed in (Table 1). Total 60 consecutive patients (55 men, 5 women, male: female, 11:1) were included in the study. Mean age was $48 \pm 10$ years. All were having angina pectoris (Canadian Cardiovascular Society, CCS class III or IV). 18 (30\%) patients had hypertension and $14(23.3 \%)$ were diabetics. $16(26.7 \%)$ were smoker and 8 $(13.3 \%)$ had dyslipidemia. $4(6.7 \%)$ had family history of ischemic heart disease. $36(60 \%)$ patients were presented with prior myocardial infarction.

Table 1. Base line clinical characteristics of the patients $(\mathrm{N}=60)$.

\begin{tabular}{|c|c|c|}
\hline Varlables & $\begin{array}{c}\text { Numbers } \\
\text { (Meant8D) }\end{array}$ & $\begin{array}{c}\text { Percent } \\
\text { (\%) }\end{array}$ \\
\hline Age & $48 \pm 10$ & - \\
\hline Male: Female & $11: 1$ & * \\
\hline Hypertension & 18 & $(30 \% 6)$ \\
\hline Diabetes mellitus & 14 & (233\%) \\
\hline Dyslipidemia & 8 & (13.3\%) \\
\hline Smoking habit & 16 & $(26.7 \%)$ \\
\hline $\begin{array}{l}\text { Family history of ischemic heart } \\
\text { disease }\end{array}$ & 4 & $(6.7 \%)$ \\
\hline Angina CCS class III or IV & 60 & $(100 \%)$ \\
\hline Prior myocardial infarction & 36 & $\left(60^{2} 6\right)$ \\
\hline
\end{tabular}

All the data are in total number, percent or mean \pm standard deviation. CCS, Canadian Cardiovascular Society

\section{Angiographic and Procedural Characteristics}

Table 2 summarizes the angiographic and procedural characteristics. Total 87 diseased vessels were diagnosed among which 60 were CTOs in 60 patients. 75 vessels were treated and 75 stents were deployed among which 40 (53.3\%) were drug eluting stents (DES). 41 (54.7\%) stents were placed in 
left anterior descending artery (LAD), $23(30.7 \%)$ in right coronary artery (RCA) and $11(14.6 \%)$ in left circumflex artery (LCX).

Table 2. Angiographic and Procedural Characteristics of the patients $(\mathrm{N}=60)$.

\begin{tabular}{|l|c|c|}
\hline Variables & Numbers & Percent (\%) \\
\hline Total number of disensed vesacls & 87 & $(100 \%)$ \\
\hline Total number of vesaels treaied & 75 & $(\mathbf{8 6 . 2 \% )}$ \\
\hline Total number of stents placed & 75 & $(86.2 \%)$ \\
\hline Total number of BMS deployed & 35 & $(46.7 \%)$ \\
\hline Total number of DES deployed & 40 & $(53.3 \%)$ \\
\hline Number of stents placed in LAD & 41 & $(54.7 \%)$ \\
\hline Number of stents placed in RCA & 23 & $(30.7 \%)$ \\
\hline Number of stents placed in LCX & 11 & $(14.6 \%)$ \\
\hline
\end{tabular}

All the data are in total number \& percent. BMS-bare metal stent, DES-drug eluting stent, LAD- left anterior descending artery, RCA- right coronary artery, LCX- left circumflex artery

\section{Angiographic Characteristics of the Cтоs.}

Table 3 depicts the angiographic characteristics of the Сто lesions. TIMI flow grade 0 was present in $43(71.7 \%)$ and TIMI grade I flow in 17 (28.3\%) cases. Stump morphology shows $31(51.7 \%)$ with blunt or abrupt cut off, $19(31.7 \%)$ with tapered tip morphology where as in $10(16.6 \%)$ cases it was not determined. Side branches in close proximity of stump were present in $14(23.3 \%)$ cases where as it was absent in $46(76.7 \%)$ cases. Collaterals were present in 5 (8.3\%) cases. Length of the lesion $19.7 \pm 10.4 \mathrm{~mm}$ and reference diameter of the diseased vessel was $2.8 \pm 0.5 \mathrm{~mm}$.

Table 3. Angiographic Characteristics of the CTOs ( $\mathrm{N}=60)$.

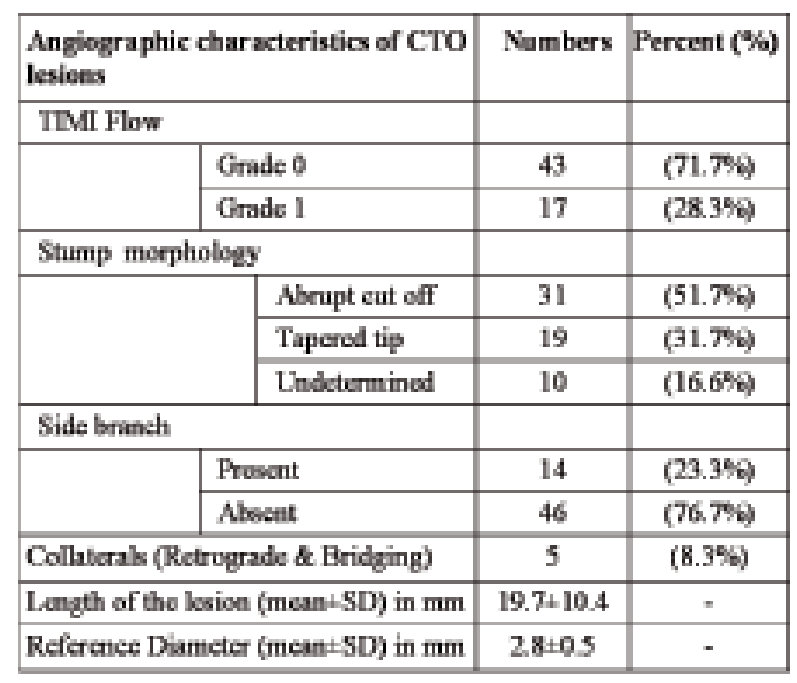

All the data are in total number, percent or mean \pm standard deviation. TIMIThrombolysis in Myocardial Infarction
Clinical, Angiographic, Procedural and adverse outcome

Table 4 shows the Clinical, Angiographic, Procedural success in 60 CTOs. Clinical success in 47 (78.3\%) cases, angiographic success in $48(80.0 \%)$ cases and procedural success in $44(66.7 \%)$ cases were achieved. PCI was failed in 12 $(20.0 \%)$ cases. Dissection and false lumen created in 4 (6.7\%) cases. Acute myocardial infarction (MI), Acute left ventricular failure (LVF) and Malignant arrhythmias were encountered in $3(5.0 \%), 4(6.7 \%)$ and $6(10.0 \%)$ respectably.

Table 4. Clinical, Angiographic, Procedural and adverse outcome ( $\mathrm{N}=60)$.

\begin{tabular}{|c|c|c|}
\hline $\begin{array}{l}\text { Clinieal, Angiegraphie \& } \\
\text { Proctdural results }\end{array}$ & Numbers & Pereent $(\%)$ \\
\hline Clinical Saceess & 47 & $(78.3 \%)$ \\
\hline Angiogruphie Sucoess & 48 & $(80.0 \%)$ \\
\hline Prosedaral Suocess & 44 & (66.7\%) \\
\hline Dissectica and Falve humen & 04 & $(6.7 \%)$ \\
\hline Acute myocardial infaretion & 03 & $(5.0 \%)$ \\
\hline Acute loft ventrieular failure & 04 & $(6.7 \%)$ \\
\hline Malignint arrhythmias (VT, VF) & 06 & $(10.0 \%)$ \\
\hline Failkd PCI & 7 & (11.7\%) \\
\hline Acarte in-stent thrombasis & 1 & $(1.7 \%)$ \\
\hline Repent Revascularization & 0 & $(0.0 \%)$ \\
\hline Death & 0 & $(0.0 \%)$ \\
\hline
\end{tabular}

All the data are in total number \& percent. PCI-Percutaneous coronary intervention. VT-Ventricular tachycardia, VF- Ventricular fibrillation.

\section{Discussion}

Previous studies have demonstrated that intervention for СТО accounts for about $10 \%$ of all $\mathrm{PCI}$ procedures. 6,9 Although PCI for СТO remains a difficult task usually associated with low technical success rate and high incidence of restenosis, successful PCI for СТО has been shown to alleviate anginal symptoms, improve left ventricular ejection fraction, decrease the need for coronary bypass graft surgery, and prolong life. $5,6,10-13$ The present study included of patients who had undergone PCI for СТО during last four years in our institute.

The presence of viable myocardium distal to occluded vascular bed is important for both PCI decision-making and clinical benefits. ${ }^{4}$ This may be observed by clinical symptoms, objective evidence of myocardial ischemia or presence of angiographic collaterals. In our study, all patients were selected specifically as they had symptomatic angina and/or documented myocardial ischemia. Most of patients had angina-free survival rate at discharge, suggesting that patients with CTO can benefit from successful PCI when indicated. 
Procedural success rate of PCI for CTO lesions was before the advent of stent. $2,14-16$ During the last 15 years, advances in medical devices and technical skill have made great impact on PCI for CTO, with procedural success rate reaching 70\% or greater in most centers. $5,6,17$ Although the patients in this study had more unfavorable CTO characteristics including longer duration of occlusion, presence of bridging collaterals, abrupt missing stump and $>15 \mathrm{~mm}$ long lesions, both procedural and clinical success rates $(66.7 \%$ and $78.3 \%$, respectively) were similar to those previously reported. The overall incidence of in-hospital adverse events (MI-5\%, LVF$6.7 \%$ and arrhythmias- $10 \%$, death- $0 \%$ ) were low suggesting that PCI for CTO can obtain a high procedural success rate and satisfactory acute outcomes at experienced hands providing that the patients and lesions were carefully selected.

The most common cause of procedural failure in negotiating CTO is the difficulties in crossing the guide-wire or balloon catheter through totally occluded segments. Proper guidewire selection and meticulous steering techniques are acknowledged as some of the most important issues in successful PCI for CTO. Saito et al. ${ }^{18}$ demonstrated that application of guide-wires with tapered tip improved the success rate of PCI for CTO from $67 \%$ to $81 \%$. In our practice, use of CTO-specific wires such as Conquest (tapered wire) or Miracle (hydrophobic-coated) and Shinobi (hydrophiliccoated stiff wires) is limited. Although in this study our only armament was skill and patience with usual equipments. On the other hand, special wire techniques including retrograde wire, parallel wire, buddy wire and multi-wire plaque crushing techniques may also be useful based on lesion characteristics.

Earlier studies have reported various CTO characteristics including duration of occlusion, morphology of occluded site and segments, significantly influence the success rate of PCI for CTO. 4,5,19,20 In accordance with those studies, we also found that CTO duration $>12$ months, an abrupt missing stump, bridging collaterals, lesion length $>15 \mathrm{~mm}$, moderate to severe calcification, tortuosity of proximal vessel and ostial or distal location of CTO lesions were unfavorable factors of procedural success.

Drug eluting stents (DES) have been widely used to reduce in-stent restenosis nowadays. Recent studies had reported that DES implantation improved long-term outcomes after successful PCI of CTO compared with bare metal stents. ${ }^{21,22}$ In this study 40 patients out of total 60 patients with CTO treated with paclitaxel or Sirolimus eluting stentsIn conclusion, PCI for CTOs remains a difficult domain in the field of interventional cardiology. However, it is possible to obtain a relatively high procedural success rate in experienced centers by skilled operators. The major issues regarding improvement of success rate are related to careful selection of patients, scrutinizing the minute details about angio- graphic morphologies of CTO, proper use of interventional devices (especially for guiding catheters and guide-wires), and collaboration of the whole team.

\section{References}

1. Meier B. Chronic total coronary occlusion angioplasty. Cathet Cardiovasc Diagn 1989;17:212-17

2. Ishizaka N, Issiki T, Saeki F, et al. Angiographic follow-up after successful percutaneous coronary angioplasty for chronic total coronary occlusion: Experience in 110 consecutive patients. Am Heart J 1994;127:8-12

3. TIMI study group. The Thrombolysis and Myocardial Infarction (TIMI) trial: phase I findings. $N$ Engl $J$ Med 1997;133:393-99

4. Puma JA, Sketch MH Jr, Tcheng JE, et al. Percutaneous revascularization of chronic coronary occlusions: an overview. J Am Coll Cardiol 1995;26:1-11

5. Noguchi T, Miyazaki MDS, Morii I, et al. Percutaneous transluminal coronary angioplasty of chronic total occlusions: determinants of primary success and long term clinical outcome. Catheter Cardiovasc Interv 2000;49:258-64

6. Suero JA, Marso SP, Jones PG, et al. Procedural outcomes and long-term survival among patients undergoing percutaneous coronary intervention of a chronic total occlusion in native coronary arteries: a 20-year experience. $\mathrm{J} \mathrm{Am} \mathrm{Coll}$ Cardiol. 2001;38:409-14

7. Tan KH, Sulke N, Taub NA, Watts E, Karani S, Sowton E. Determinants of success of coronary angioplasty in patients with a chronic total occlusion: a multiple logistic regression model to improve selection of patients. Br Heart $J$. 1993;70:126-31

8. Rentrop KP, Cohen M, Blanke H, Phillips RA. Changes in collateral channel filling immediately after controlled coronary artery occlusion by an angioplasty balloon in human subjects. J Am Coll Cardiol. 1985;5:587-92

9. Aziz S, Ramsdale DR. Chronic total occlusions a stiff challenge requiring a major breakthrough: is there light at the end of the tunnel? Heart 2005;91 Suppl III:iii42-iii48

10. Warren RJ, Black AJ, Valentine PA, Manolas EG, Hunt D. Coronary angioplasty for chronic total occlusion reduces the need for subsequent coronary bypass surgery. Am Heart $J$ 1990;120:270-74

11. Kishi K, Hiasa Y, Kinoshita M, Kondo N, Fujinaga H,Ohtani $\mathrm{R}$, et al. Efficacy and safety of percutaneous transluminal coronary angioplasty of other coronary arteries in patients with chronic total occlusion of the left anterior descending artery. J Cardiol 1995; 25:303-08

12. Gottschall CA, Trindade II, Miler VV. Changes in left ventricular function after coronary recanalization by percuta- 
neous transluminal coronary angioplasty (PTCA). J Invasive Cardiol 1997; 9:146-53

13. Chung CM, Nakamura S, Tanaka K, Tanigawa J, Kitano K, Akiyama $\mathrm{T}$, et al. Effect of recanalization of chronic total occlusions on global and regional left ventricular function in Patients with or without previous myocardial infarction. Catheter Cardiovasc Interv 2003; 60:368-74

14. Stone GW, Rutherford BD, McConahay DR, Johnson WL Jr, Giorgi LV, Ligon RW, et al. Procedural outcome of angioplasty for total coronary artery occlusion: an analysis of 971 lesions in 905 patients. $J$ Am Coll Cardiol 1990; 15:849-56

15. Ruocco NA Jr, Ring ME, Holubkov R, Jacobs AK, Detre KM, Faxon DP. Results of coronary angioplasty of chronic total occlusions (the National Heart, Lung, and Blood Institute 1985-1986 Percutaneous Transluminal Angioplasty Registry). Am J Cardiol 1992;69:69-76

16. Ivanhoe RJ, Weintraub WS, Douglas JS Jr, Lembo NJ, Furman M, Gershony G, et al. Percutaneous transluminal coronary angioplasty of chronic total occlusions. Primary success, restenosis, and long-term clinical follow-up. Circulation 1992; 85:106-15

17. Rubartelli P, Verna E, Niccoli L, Giachero C, Zimarino M, Bernardi $\mathrm{G}$, et al. Coronary stent implantation is superior to balloon angioplasty for chronic coronary occlusions. Six-year clinical follow-up of the GISSOC trial. J Am Coll Cardiol
2003; 41: 1488-92

18. Saito S, Tanaka S, Hiroe Y, Miyashita Y, Takahashi S, Satake $\mathrm{S}$, et al. Angioplasty for chronic total occlusion by using tapered-tip guidewires. Catheter Cardiovasc Interv 2003; 59: 305-11

19. Suzuki T, Hosokawa H, Yokoya K, Kojima A, Kinoshita Y, Miyata S, et al. Time-dependent morphologic characteristics in angiographic chronic total coronary occlusions. $\mathrm{Am} \mathrm{J}$ Cardiol 2001; 88:167-69

20. Dong S, Smorgick Y, Nahir M, Lotan C, Mosseri M, Nassar $\mathrm{H}$, et al. Predictors for successful angioplasty of chronic totally occluded coronary arteries. J Interven Cardiol 2005; 18:1-7

21. Werner GS, Krack A, Schwarz G, Prochnau D, Betge S, Figulla HR. Prevention of lesion recurrence in chronic total coronary occlusions by paclitaxel-eluting stents. $\mathrm{J} \mathrm{Am} \mathrm{Coll}$ Cardiol 2004;44:2301-06

22. Ge L, Lakovou L, Cosgrave J, Chieffo A, Montorfano M, Michev I, et al. Immediate and mid-term outcomes of sirolimus-eluting stent implantation for chronic total occlusions. Eur Heart J 2005; 26:1056-62 